\title{
The efficacy and safety of the naltrexone/bupropion combination for the treatment of obesity: an update
}

\author{
Georgios A. Christou, Dimitrios N. Kiortsis \\ Laboratory of Physiology, Medical School, University of loannina, loannina, Greece
}

\begin{abstract}
OBJECTIVE: The combination of $32 \mathrm{mg}$ naltrexone and $360 \mathrm{mg}$ bupropion prolonged release (NB32) was recently approved by both the food and drug administration (FDA) and the European medicines agency (EMA) as an adjunct to a comprehensive lifestyle intervention to achieve weight loss. DESIGN: Randomized controlled trials with naltrexone/bupropion prolonged release were selected through a search based on PubMed listings using the terms "bupropion AND naltrexone". RESULTS: NB32 treatment resulted in 5.0-9.3\% weight loss, while the placebo-subtracted weight loss was 3.2-5.2\% during 56 weeks of treatment. The proportion of treated patients with $\geq 5 \%$ weight loss was $45-66 \%$, while the placebo-subtracted proportion was $23-34 \%$. NB32 was associated with a decrease in waist circumference, serum triglycerides and insulin resistance and an increase in high-density lipoprotein-cholesterol (HDL-C). Blood pressure mainly remained stable but there was a small increase in heart rate. The most common side effects were nausea, constipation, headache and vomiting. Serious adverse effects, which were very rare, included suicidal thoughts and seizures. In the majority of patients NB32 treatment was well tolerated. CONCLUSIONS: Naltrexone/bupropion combination appears to be an effective adjunct to a comprehensive lifestyle intervention in order to achieve weight loss and treat obesity-related comorbidities.
\end{abstract}

Key words: Bupropion, Naltrexone, Obesity

\section{INTRODUCTION}

Obesity is an epidemic disease with a prevalence in the USA today of approximately $35 \% .{ }^{1}$ Obesity is associated with cardiovascular consequences, such as hypertension and type 2 diabetes mellitus, and

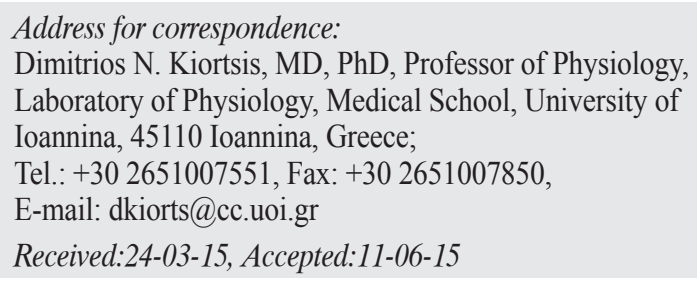

has been linked to some types of cancer as well to osteoarthritis and sleep apnea. ${ }^{1}$ The recent guidelines for the management of overweight and obese adults underline that the mainstay of the treatment of obesity is a comprehensive lifestyle intervention consisting of a hypocaloric diet, exercise and behavioral strategies. ${ }^{1}$ For individuals with a Body Mass Index (BMI) $\geq 30 \mathrm{Kg} / \mathrm{m}^{2}$ or $\mathrm{BMI} \geq 27 \mathrm{Kg} / \mathrm{m}^{2}$ with at least one obesity-associated comorbidity, pharmacotherapy can be considered as an adjunct to comprehensive lifestyle intervention to help achieve the target of at least $5 \%$ weight loss and health goals. The lipase 
inhibitor orlistat is an old drug approved by both the European medicines agency (EMA) and the food and drug administration (FDA). ${ }^{2}$ Although rimonabant and sibutramine were withdrawn from the market a few years ago, new anti-obesity drugs have become available. ${ }^{3,4}$ The FDA has approved the following drugs for obesity treatment: the serotonin $2 \mathrm{C}$ receptor agonist lorcaserin, the dopamine and GABAergic combination of phentermine/topiramate, the combination of the opioid antagonist naltrexone and pro-opiomelanocortin (POMC) activator bupropion and the glucagon-like peptide-1 (GLP-1) receptor agonist liraglutide..$^{5-9}$ Among these four drugs only naltrexone/bupropion and liraglutide are approved by the EMA for obesity treatment. This article presents a critical review of the studies investigating the clinical efficacy and safety of the bupropion/naltrexone combination.

\section{METHODS}

A literature search based on PubMed listings up to 24 March 2015 using "bupropion AND naltrexone" as the search terms identified 111 articles, the abstracts of which were examined. Only original research articles were considered eligible for inclusion in the review.

\section{BUPROPION}

Bupropion is primarily used as an antidepressant and smoking cessation aid. It is recommended to be taken for these indications at a daily dose of $300 \mathrm{mg}$. Bupropion inhibits reuptake of dopamine and noradrenaline. ${ }^{10}$ These cathecholamines stimulate POMC neurons in the arcuate nucleus of the hypothalamus. ${ }^{11}$ POMC is a precursor for $\alpha$-melanocyte stimulating hormone $(\alpha-\mathrm{MSH})$ and $\beta$-endorphin. $\alpha$-MSH acts on melanocortin- 4 receptors to decrease food intake, whereas $\beta$-endorphin sends feedback inhibition to POMC neurons, attenuating this effect (Figure 1). This autoinhibitory feedback possibly underlies the limited efficacy of bupropion monotherapy regarding weight loss. Bupropion monotherapy appears to induce a weight loss of less than $5 \%$ in the long term. ${ }^{11-13}$ The mean elimination half-life of bupropion is 21 hours.

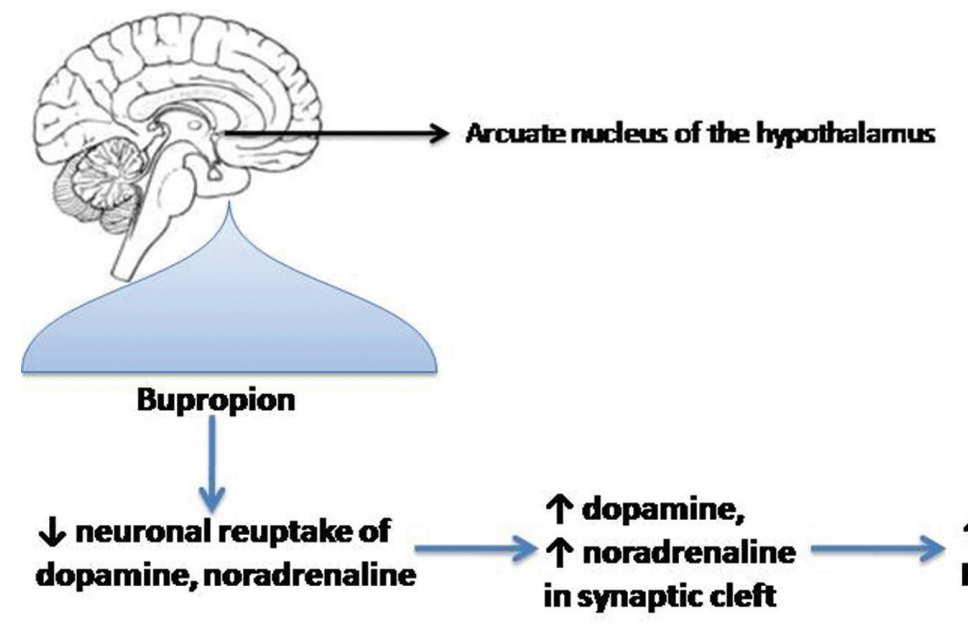

$\uparrow$ stimulation of in synaptic clefi
POMC neurons<smiles>[C]1CCC2CCC1C2</smiles>

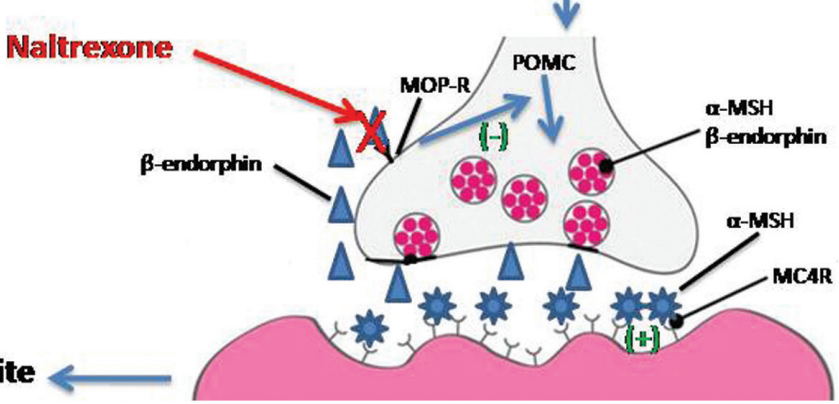

Figure 1. Mechanism of bupropion/naltrexone-induced weight loss. $\alpha$-MSH: $\alpha$-melanocyte stimulating hormone, MC4R: melanocortin-4 receptor, MOP-R: $\mu$-opioid receptor, POMC: pro-opiomelanocortin. 
Bupropion is extensively metabolized in humans to 3 active metabolites: hydroxybupropion (hepatic metabolism via CYP2B6), threohydrobupropion and erythrohydrobupropion (nonCYP metabolism). There is a potential for drug-drug interactions, particularly with those agents that are metabolized by the cytochrome CYP2B6 (cyclophosphamide, propofol, tamoxifen, valproic acid, etc.). Bupropion is eliminated primarily in the form of its metabolites: $87 \%$ by the kidneys and $10 \%$ in feces.

The most common side effects of bupropion are insomnia and headache. Epileptic seizures are the most serious adverse effect (0.4\%). Moreover, bupropioninduced hypertension can occur. Bupropion should not be prescribed to individuals with epilepsy or other conditions that lower the seizure threshold, such as anorexia nervosa, bulimia nervosa, brain tumors, alcohol and benzodiazepine use or withdrawal. It should not be coadministered with monoamine oxidase inhibitors (MAOIs). When switching from MAOIs to bupropion, a washout period of two weeks between these medications is recommended. Moreover, caution should be exercised in patients with liver damage, severe kidney disease and severe hypertension.

\section{NALTREXONE}

Naltrexone is an opioid antagonist with a high affinity for the $\mu$-opioid receptor. It is approved for the treatment of alcoholism and opioid addiction. Naltrexone is recommended to be taken for these indications at a daily dose of $50 \mathrm{mg}$. Naltrexone reduces food intake possibly through the blockade of $\beta$-endorphin action at the $\mu$-opioid receptor, thus preventing autoinhibition of POMC neurons (Figure 1). ${ }^{11}$ Naltrexone monotherapy appears to induce a longterm weight loss of less than 5\% and may be less effective than bupropion monotherapy regarding the magnitude of weight loss. ${ }^{11-13}$ Naltrexone is subject to significant first-pass metabolism with $5-40 \%$ oral bioavailability. The activity of naltrexone is due to both parent and the 6- $\beta$-naltrexol metabolite. Naltrexone is excreted primarily by the kidneys. The mean elimination half-life for naltrexone and 6- $\beta$-naltrexol is 4 hours and 13 hours, respectively.

The most common side effect of naltrexone is nausea. Naltrexone should not be used by subjects with liver failure or those with recent opioid use. The most important drug interaction is with opioids.

\section{NALTREXONE/BUPROPION}

Naltrexone/bupropion combination is available in the market in the form of a fixed-dose combination of naltrexone prolonged release (PR) and bupropion PR in a single tablet (NB32). Each tablet contains $8 \mathrm{mg}$ naltrexone PR and $90 \mathrm{mg}$ bupropion PR. The FDA approved naltrexone/bupropion combination marketed under the name Contrave for the treatment of obesity in September 2014. The EMA approved naltrexone/ bupropion marketed under the name Mysiba for the treatment of obesity in March 2015. Dose titration during initiation of naltrexone/bupropion treatment aims at the reduction of the main side effect, which is nausea:

- Week 1: 1 tablet once daily every morning.

- Week 2: 1 tablet every morning and evening.

- Week 3: 2 tablets every morning and 1 in the evening.

- Week 4-onward: 2 tablets every morning and evening.

The target daily dose is $32 \mathrm{mg}$ naltrexone/360 mg bupropion (2 tablets twice daily). Patients using NB32 should be evaluated after 12 weeks to determine whether the treatment is efficacious. If the weight loss is less than 5\%, NB32 should be discontinued, as it is unlikely that the patient will achieve and sustain clinically meaningful weight loss with continued treatment. Notably, the $32 \mathrm{mg}$ daily dose of naltrexone contained in NB32 is lower than the recommended daily dose of $50 \mathrm{mg}$ naltrexone monotherapy for the treatment of alcoholism and opioid addiction. Table 1 shows data from the randomized clinical trials investigating the efficacy and safety of naltrexone/ bupropion combination.

\section{Weight loss effect}

NB32 has consistently been shown to be superior to placebo and naltrexone monotherapy, as well as to bupropion monotherapy, regarding the magnitude of weight loss in all relevant studies. ${ }^{8,11-16}$ Notably, the recommended dose on the label of $32 \mathrm{mg}$ naltrexone PR and $360 \mathrm{mg}$ bupropion PR was tested only in the 
Table 1. Data of phase III clinical trials using the naltrexone/bupropion combination.

\begin{tabular}{|c|c|c|c|c|c|c|}
\hline Study & Duration & Patients & Treatment groups & Dropout & Weight loss & $\geq 5 \%$ weight loss \\
\hline COR-I ${ }^{8}$ & 56 weeks & $\begin{array}{l}\mathrm{n}=1742 \\
\text { Inclusion criteria: } \\
\cdot \mathrm{BMI}=30-45 \mathrm{Kg} / \mathrm{m}^{2} \text { or } \\
\cdot \mathrm{BMI}=27-45 \mathrm{Kg} / \mathrm{m}^{2}, \\
\text { hypertension, } \\
\text { dyslipidaemia }\end{array}$ & $\begin{array}{l}\text { 1) } 32 \mathrm{mg} \text { NAL }+360 \mathrm{mg} \text { BUP } \\
\text { 2) } 16 \mathrm{mg} \text { NAL+360 mg BUP } \\
\text { 3) Placebo } \\
\text { Behavioral therapy: ancillary }\end{array}$ & $\begin{array}{l}49 \% \\
51 \% \\
50 \%\end{array}$ & $\begin{array}{l}-6.1 \% \\
-5.0 \% \\
-1.3 \%\end{array}$ & $\begin{array}{l}48 \% \\
39 \% \\
16 \%\end{array}$ \\
\hline COR-II ${ }^{15}$ & 56 weeks & $\begin{array}{l}\mathrm{n}=1496 \\
\text { Inclusion criteria: } \\
\text { as in COR-I } \\
\text { Exclusion criteria: DM }\end{array}$ & $\begin{array}{l}\text { 1) } 32 \text { mg NAL+360 mg BUP } \\
\text { 2) Placebo } \\
\text { Behavioral therapy: ancillary }\end{array}$ & $\begin{array}{l}46 \% \\
46 \%\end{array}$ & $\begin{array}{l}-6.4 \% \\
-1.2 \%\end{array}$ & $\begin{array}{l}51 \% \\
17 \%\end{array}$ \\
\hline COR-BMOD $^{14}$ & 56 weeks & $\begin{array}{l}\mathrm{n}=793 \\
\text { Inclusion criteria: } \\
\text { as in COR-I } \\
\text { Exclusion criteria: } \\
\text { DM }\end{array}$ & $\begin{array}{l}\text { 1) } 32 \mathrm{mg} \text { NAL+360 mg BUP } \\
\text { 2) Placebo } \\
\text { Behavioral therapy: intensive }\end{array}$ & $\begin{array}{l}42 \% \\
42 \%\end{array}$ & $\begin{array}{l}-9.3 \% \\
-5.1 \%\end{array}$ & $\begin{array}{l}66 \% \\
43 \%\end{array}$ \\
\hline COR-Diabetes ${ }^{16}$ & 56 weeks & $\begin{array}{l}\mathrm{n}=505 \\
\text { Inclusion criteria: } \\
\text { Type } 2 \mathrm{DM}, \\
\mathrm{BMI}=27-45 \mathrm{Kg} / \mathrm{m}^{2}, \\
\mathrm{HbA} 1 \mathrm{c}=7-10 \%, \\
\mathrm{Glc}<270 \mathrm{mg} / \mathrm{dL}\end{array}$ & $\begin{array}{l}\text { 1) } 32 \mathrm{mg} \text { NAL+360 mg BUP } \\
\text { 2) Placebo } \\
\text { Behavioral therapy: ancillary }\end{array}$ & $\begin{array}{l}48 \% \\
41 \%\end{array}$ & $\begin{array}{l}-5.0 \% \\
-1.8 \%\end{array}$ & $\begin{array}{l}45 \% \\
19 \%\end{array}$ \\
\hline NB-201 ${ }^{12}$ & 48 weeks & $\begin{array}{l}\mathrm{n}=419 \\
\text { Inclusion criteria: } \\
\mathrm{BMI}=30-40 \mathrm{Kg} / \mathrm{m}^{2}, \\
\text { nonsmokers, } \\
\text { normotensive, } \\
\mathrm{LDL}-\mathrm{C}<190 \mathrm{mg} / \mathrm{dL}, \\
\mathrm{TG}<400 \mathrm{mg} / \mathrm{dL}, \\
\mathrm{Glc}<140 \mathrm{mg} / \mathrm{dL}\end{array}$ & $\begin{array}{l}\text { 1) } 16 \mathrm{mg} \mathrm{NAL}+400 \mathrm{mg} \text { BUP } \\
\text { 2) } 32 \mathrm{mg} \text { NAL+400 mg BUP } \\
\text { 3) } 48 \mathrm{mg} \text { NAL+400 mg BUP } \\
\text { 4) } 400 \mathrm{mg} \mathrm{BUP} \\
\text { 5) } 48 \mathrm{mg} \mathrm{NAL} \\
\text { 6) placebo }\end{array}$ & $\begin{array}{l}45 \% \\
36 \% \\
63 \% \\
33 \% \\
46 \% \\
32 \%\end{array}$ & $\begin{array}{l}-5.4 \% \\
-5.4 \% \\
-4.3 \% \\
-2.7 \% \\
-1.2 \% \\
-0.8 \%\end{array}$ & $\begin{array}{l}52 \% \\
51 \% \\
39 \% \\
26 \% \\
10 \% \\
15 \%\end{array}$ \\
\hline Greenway et $\mathrm{al}^{11}$ & 24 weeks & $\begin{array}{l}\mathrm{n}=238 \\
\text { Inclusion criteria: } \\
\mathrm{BMI}=30-40 \mathrm{Kg} / \mathrm{m}^{2}\end{array}$ & $\begin{array}{l}\text { 1) } 50 \mathrm{mg} \text { NAL+300 mg BUP } \\
\text { 2) } 300 \mathrm{mg} \mathrm{BUP+placebo} \\
\text { 3) } 50 \mathrm{mg} \mathrm{NAL}+\text { placebo } \\
\text { 4) Placebo+placebo }\end{array}$ & $\begin{array}{l}43 \% \\
32 \% \\
43 \% \\
36 \%\end{array}$ & $\begin{array}{l}-3.7 \% \\
-3.2 \% \\
-1.7 \% \\
-0.6 \%\end{array}$ & $\begin{array}{l}32 \% \\
26 \% \\
15 \% \\
12 \%\end{array}$ \\
\hline
\end{tabular}

BMI: Body mass index; BUP: Bupropion; DM: Diabetes mellitus; Glc: Fasting blood glucose; HbA1c: Glycated hemoglobin; LDL-C: Low density lipoprotein-cholesterol; NAL: Naltrexone; TG: Serum triglycerides.

following studies: COR-I, COR-II, COR-BMOD, COR-Diabetes. In all these studies there were at least 2 study arms including NB32 and placebo treatment, while all participants adhered to a comprehensive lifestyle intervention. This comprehensive lifestyle intervention included an ancillary behavioral therapy in COR-I, COR-II, COR-Diabetes and intensive behavioral group lifestyle modification counseling in COR-BMOD. NB32 resulted in 5.0-9.3\% weight loss, while the placebo-subtracted weight loss was $3.2-5.2 \%$ during 56 weeks of treatment. The proportion of treated patients with $\geq 5 \%$ weight loss was $45-66 \%$, while the placebo-subtracted proportion was $23-34 \%$. Due to the well known efficacy of bupropion in smoking cessation, obese subjects who wish to quit smoking may be good candidates for NB32 as an aid to avoid weight gain during cessation of smoking. Indeed, NB32 treatment plus behavioral counseling 
for 24 weeks resulted in no significant change of body weight in overweight or obese subjects after cessation of smoking. ${ }^{17}$

\section{Effects on metabolic and cardiovascular parameters}

NB32 treatment resulted in greater reduction of waist circumference, serum insulin levels, fasting blood glucose and serum triglycerides and greater increase in high density lipoprotein-cholesterol (HDL-C) compared with placebo. ${ }^{8,14-16}$ The placebosubtracted NB32-induced changes were 2.1-4.6 cm for waist circumference, $3.1-14.9 \%$ for serum insulin, $1.5-2.9 \%$ for fasting blood glucose, $8.1-10.4 \%$ for serum triglycerides and $2.7-7.2 \%$ for HDL-C. Low-density lipoprotein-cholesterol decreased less consistently during NB32 treatment compared with the other metabolic parameters. The decrease in waist circumference can plausibly be attributed to the associated reduction of visceral fat mass. ${ }^{18,19}$ To our knowledge, studies investigating whether naltrexone/ bupropion treatment is linked to the favorable changes in parameters of lipoprotein metabolism and insulin resistance independently of the associated weight loss have never been performed. In this respect, it is not clear whether these favorable effects on the metabolic profile are specific to naltrexone/bupropion treatment and to what extent this can be attributed to the weight loss per se. Further studies are needed to clarify this issue. The effects of naltrexone/bupropion treatment on other metabolic parameters, including lipokines, have not been studied as yet.

In the studies using NB32, placebo treatment combined with comprehensive lifestyle intervention led to reduction of systolic blood pressure (SBP) and diastolic blood pressure (DBP), though to no change in heart rate (HR) ${ }^{8,14-16} \mathrm{NB} 32$ combined with comprehensive lifestyle intervention resulted in mild fluctuations of SBP and DBP within $2 \mathrm{mmHg}$ around baseline values and small increases in HR up to 2 bpm. Placebo treatment caused greater decreases or similar changes in SBP and DBP compared with NB32. NB32 caused a small increase or no change in HR compared with placebo. Therefore, NB32 per se tended to cause mild increases in SBP, DBP and HR. Greater NB32-induced weight loss was associated with greater reductions in mean BP. These effects are plausibly attributed to the sympathomimetic effects of bupropion, which acts as a norepinephrine and dopamine reuptake inhibitor. ${ }^{20}$

\section{Adverse events}

The adverse events with NB32 can be attributed to the individual actions of naltrexone and bupropion. The most frequent side effects of this combination were nausea $(29-42 \%)$, constipation (16-24\%), headache (14-24\%), vomiting (9-18\%), dizziness (7-15\%), insomnia (8-11\%), dry mouth (6-9\%) and diarrhea (5$15 \%)$. Side effects were in general mild to moderate, occurred early in treatment during dose titration and did not usually lead to discontinuation of treatment. ${ }^{8}$ The most common adverse event was mild nausea, which was mainly caused by naltrexone.

NB32 was associated very rarely with serious side effects. Specifically, there was an increased risk of suicidal thoughts, attributed to bupropion. NB32 can cause seizures, due to bupropion, and must not be used in patients who have seizure disorders. NB32 should be discontinued and not restarted in patients who experience a seizure while being treated with this drug combination. As mentioned above, NB32 might raise $\mathrm{BP}$ and HR and should not be used in patients with uncontrolled hypertension. The clinical significance of the mild increases in BP and HR observed with NB32 treatment is unclear, especially for patients with heart-related and cerebrovascular disease, since patients with a history of heart attack or stroke in the previous six months, life-threatening arrhythmias or congestive heart failure were excluded from the clinical trials. BP and pulse should be measured prior to initiation of treatment and should be monitored at regular intervals.

Other products containing bupropion should not be taken along with NB32. This drug combination should not be used in patients who have eating disorders (bulimia or anorexia nervosa). NB32 combination should not be coadministered with opioids and should not be used by subjects experiencing acute opiate withdrawal. NB32 is contraindicated during the abrupt discontinuation of alcohol, benzodiazepines and antiepileptic drugs. Pregnancy or desire for pregnancy are contraindications for NB32.

\section{Limitations of studies}

Limitations of studies investigating the clinical effects of NB32 include the overrepresentation of 
women, except for the COR-Diabetes study. Also, the proportion of nonwhite participants in these studies was too small. Moreover, subjects with $\mathrm{BMI} \geq 45$ $\mathrm{Kg} / \mathrm{m}^{2}$ were excluded and thus the efficacy of NB32 in these individuals is unknown. The maximal duration of these studies was 56 weeks. Therefore, the efficacy of NB32 beyond 56 weeks is only presumptive; nevertheless, is clinically important because the most challenging part of the obesity treatment is the longterm maintenance of weight loss rather than the achievement of initial weight loss.

\section{CONCLUSIONS}

The $32 \mathrm{mg}$ naltrexone/360 mg bupropion combination (NB32) constitutes a form of adjunctive pharmacotherapy to a comprehensive lifestyle intervention with an established additive efficacy in producing weight loss. Moreover, it leads to favorable changes in metabolic profile consistent with the associated weight loss, except for BP, which mainly remains stable during this treatment. However, the relative efficacy of NB32 compared with other anti-obesity drugs is unknown and head-to-head randomized trials are needed. NB32 appears to be a relatively safe pharmacotherapy, though caution is required, especially for subjects with uncontrolled hypertension or suicidal thoughts. Further well-designed randomized clinical trials are needed including a larger proportion of men and people of various races and lasting for a longer time period.

\section{REFERENCES}

1. Jensen MD, Ryan DH, Apovian CM, et al, 20142013 AHA/ACC/TOS guideline for the management of overweight and obesity in adults: a report of the American College of Cardiology/American Heart Association Task Force on Practice Guidelines and The Obesity Society. Circulation 129: 25 Suppl 2: 102-138.

2. Kiortsis DN, Filippatos TD, Elisaf MS, 2005 The effects of orlistat on metabolic parameters and other cardiovascular risk factors. Diabetes Metab 31: 15-22.

3. Christopoulou FD, Kiortsis DN, 2011 An overview of the metabolic effects of rimonabant in randomized controlled trials: potential for other cannabinoid 1 receptor blockers in obesity. J Clin Pharm Ther 36: 10-18.

4. Filippatos TD, Kiortsis DN, Liberopoulos EN, Mikhailidis DP, Elisaf MS, 2005 A review of the metabolic effects of sibutramine. Curr Med Res Opin 21: 457-468.

5. Chan EW, He Y, Chui CS, Wong AY, Lau WC, Wong IC, 2013 Efficacy and safety of lorcaserin in obese adults: a meta-analysis of 1-year randomized controlled trials (RCTs) and narrative review on short-term RCTs. Obes Rev 14: 383-392.

6. Kiortsis DN, 2013 A review of the metabolic effects of controlled-release Phentermine/Topiramate. Hormones (Athens) 12: 507-516.

7. Iepsen EW, Torekov SS, Holst JJ, 2014 Therapies for inter-relating diabetes and obesity - GLP-1 and obesity. Expert Opin Pharmacother 15: 2487-2500.

8. Greenway FL, Fujioka K, Plodkowski RA, et al, 2010 Effect of naltrexone plus bupropion on weight loss in overweight and obese adults (COR-I): a multicentre, randomised, double-blind, placebo-controlled, phase 3 trial. Lancet 376: 595-605.

9. Pucci A, Finer N, 2015 New Medications for Treatment of Obesity: Metabolic and Cardiovascular Effects. Can J Cardiol 31: 142-152.

10. Gadde KM, Xiong GL, 2007 Bupropion for weight reduction. Expert Rev Neurother 7: 17-24.

11. Greenway FL, Whitehouse MJ, Guttadauria M, et al, 2009 Rational design of a combination medication for the treatment of obesity. Obesity (Silver Spring) 17: 30-39.

12. Greenway FL, Dunayevich E, Tollefson G, et al, 2009 Comparison of combined bupropion and naltrexone therapy for obesity with monotherapy and placebo. J Clin Endocrinol Metab 94: 4898-4906.

13. Smith SR, Fujioka K, Gupta AK, et al, 2013 Combination therapy with naltrexone and bupropion for obesity reduces total and visceral adiposity. Diabetes Obes Metab 15: 863-866.

14. Wadden TA, Foreyt JP, Foster GD, et al, 2011 Weight loss with naltrexone SR/bupropion SR combination therapy as an adjunct to behavior modification: the COR-BMOD trial. Obesity (Silver Spring) 19: 110-120.

15. Apovian CM, Aronne L, Rubino D, et al, 2013 A randomized, phase 3 trial of naltrexone SR/bupropion SR on weight and obesity-related risk factors (COR-II). Obesity (Silver Spring) 21: 935-943.

16. Hollander P, Gupta AK, Plodkowski R, et al, 2013 Effects of naltrexone sustained-release/bupropion sustained-release combination therapy on body weight and glycemic parameters in overweight and obese patients with type 2 diabetes. Diabetes Care 36: 4022-4029.

17. Wilcox CS, Oskooilar N, Erickson JS, et al, 2010 An open-label study of naltrexone and bupropion combination therapy for smoking cessation in overweight and obese subjects. Addict Behav 35: 229-234.

18. Després JP, 2012 Body fat distribution and risk of cardiovascular disease: an update. Circulation 126: 1301-1313.

19. Ross R, Janiszewski PM, 2008 Is weight loss the optimal target for obesity-related cardiovascular disease risk reduction? Can J Cardiol 24: Suppl D: 25D-31D.

20. Thase ME, Haight BR, Johnson MC, et al, 2008 A randomized, double-blind, placebo-controlled study of the effect of sustained-release bupropion on blood pressure in individuals with mild untreated hypertension. J Clin Psychopharmacol 28: 302-307. 